\title{
Pre-service English Teachers' Vocabulary Learning Strategy Use and Vocabulary Size: A Cross-sectional Evaluation
}

\author{
Seray Tanyer \\ Anadolu University, Turkey \\ Yusuf Ozturk \\ Anadolu University, Turkey
}

\begin{abstract}
After years of neglect, vocabulary has now been accepted as crucial to be able to interact in the target language. However, it may also become a challenge for learners to master a sufficient amount of vocabulary. It is argued that the use of vocabulary learning strategies leads to effective vocabulary learning. Addressing this relationship, different studies have focused on probing the dynamics of vocabulary learning. In this sense, the current study attempts to examine this issue for EFL university students who are also preservice English teachers. It aims to investigate the relationship between their vocabulary learning strategy use and vocabulary size. For this purpose, a cross-sectional and mixed research design was adapted and 80 ELT majors from 1st to 4th year participated in the study. In the three-week data gathering process, three instruments were used to measure the participants' vocabulary size and vocabulary learning strategy use. The results demonstrated that the most frequently used strategy category was determination strategies although it did not have any effect on the participants' vocabulary size. Multiple regression analysis revealed that the participants' vocabulary learning strategy use, in general, significantly explained $17.8 \%$ of the variation in their vocabulary size.
\end{abstract}

Index Terms — vocabulary learning, vocabulary size, vocabulary learning strategies, Turkish EFL learners

\section{INTRODUCTION}

Vocabulary is an important issue in language learning and an essential component of second language (L2) proficiency. After a period during which grammar was perceived as center to language learning, many researchers and educators have now recognized the essential role of vocabulary in second language learning process. In his widely referred quotation, Wilkins (1972) emphasizes the importance of vocabulary as "without grammar very little can be conveyed, without vocabulary nothing can be conveyed" (p.111). Grammar is undoubtedly vital for successful and native-like language use, but not as much as vocabulary knowledge since it is the words that help learners deliver the overall meaning. As a matter of fact, learners are also aware of the importance of vocabulary and, as Schmitt (2010) says, they don't carry around grammar books but dictionaries. Besides, for the research part, many studies (e.g. Laufer, 1992; Laufer \& Goldstein, 2004; Alderson, 2005) have been conducted to probe the dynamics of vocabulary in the second language learning process. Laufer (1992) found a close relationship between vocabulary size and reading while Laufer and Goldstein (2004) found that vocabulary accounted for $42.6 \%$ of the variance in learners' foreign language class grades. Similarly, Albrechtsen, Haastrup, and Henriksen's study (2008) revealed a high correlation between L2 vocabulary size and L2 reading ability. In a more systematic study addressing this interrelationship, vocabulary was found to have a strong relationship with reading, writing, listening and grammar (Alderson, 2005). Therefore, it can be argued that "language ability is, to quite a large extent, a function of vocabulary size" (ibid p.88).

Despite its importance in L2 performance, vocabulary has been problematic for EFL (English as a Foreign Language) learners since they need to acquire a large amount of vocabulary to be able to communicate successfully. This process is not only tricky for learners but also for EFL teachers who need to develop or adapt materials for their students to acquire a certain level of vocabulary. Although, with the advent of technology, teachers have a number of options to provide authentic materials increasing the target language exposure, the consolidation of newly encountered vocabulary by the students is still a troublesome and everlasting process. At this point, what comes forth as part of the recent movement from a predominantly teaching-oriented view to a more learner-centered one (Schmitt, 2010) is vocabulary learning strategies. Different researchers surveyed and defined learning and vocabulary learning strategies in the last decades. Rubin (1987, p.29) presented a definition of learning strategies in which learning is "the process by which information is obtained, stored, retrieved, and used". Schmitt (1997) defined 'use' as vocabulary practice rather than interactional communication and therefore, according to him, "vocabulary learning strategies could be any which affect this practice rather than broadly defined process" (Schmitt, 1997, p. 203). 
To date, the literature has proffered various vocabulary learning strategy taxonomies (Gu \& Johnson, 1996; Nation, 2001; Schmitt, 1997). Gu and Johnson (1996) formed a taxonomy with two main dimensions: metacognitive regulation and cognitive strategies, which covered six subcategories: guessing strategies, dictionary strategies, note-taking strategies, rehearsal strategies, encoding strategies and activating strategies. All of these strategies were further subcategorized, so there were 74 strategies in total. Nation (2001) shaped a general classification of vocabulary learning strategies by separating the facets of vocabulary knowledge from the sources of vocabulary knowledge and learning processes. Vocabulary learning strategies were categorized into three general groups: planning, sources and processes. On the other hand, in a more comprehensive study of vocabulary learning strategies, Schmitt (1997) organized its taxonomy according to both Oxford's (1990) classification and the Discovery/Consolidation distinction. This taxonomy was developed based on the research conducted with Japanese EFL learners and teachers' recommendations. It embodies 58 strategies that were categorized under two main headings, which were discovery strategies and consolidation strategies.

Discovery strategies are the ones related to the discovery of a new word's meaning, which has two sub-categories: social strategies and determination strategies. In this category of strategies, if learners do not know a word, they discover its meaning by guessing from their structural knowledge of the language, guessing from an L1 cognate, guessing from context, using reference materials, or asking someone else. Determination strategies facilitate gaining knowledge of a new word from the first four options. Social strategies are employed to get the meaning of a word by cooperating with others. In contrast, consolidation strategies are the ones used for remembering words once they have been encountered. This group is divided into four sub-categories such as social, memory, cognitive and metacognitive strategies. Memory strategies consist of "approaches which relate new materials to existing knowledge" while cognitive strategies are defined as "manipulation or transformation of the target language by the learner" (Schmitt, 1997; p. 205). Lastly, metacognitive strategies are characterized as "a conscious overview of the learning process and making decisions about planning, monitoring or evaluating the best way of study" (ibid p. 205). Figure 1 represents the categorization in Schmitt's (1997) taxonomy.

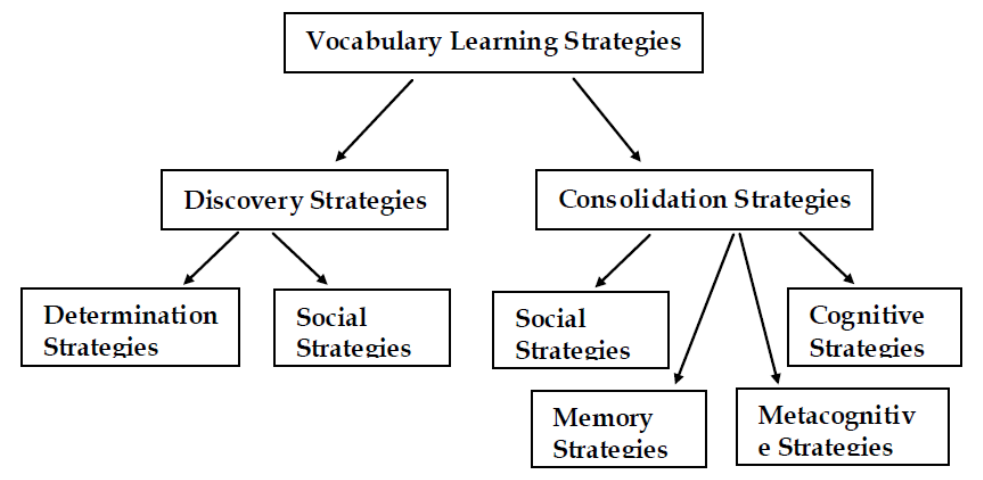

Figure 1. Schmitt's Taxonomy of Vocabulary Learning Strategies (1997, pp. 205-210)

The literature has reported on the relationship between vocabulary size and learners' strategy use. In addition to various research designs in the past (Lawson and Hogben, 1996; Schmitt, 1997; and Fan, 2003) inquiring what kind of vocabulary learning strategies language learners use, a present study of Lip (2009), with a group of Chinese EFL postsecondary students, has questioned the most frequently used and most useful vocabulary learning strategies. Some recent studies (Hamzah, et all, 2009; Kafipour, et al, 2011; Komol \& Sripetpun, 2011; Kalajahi \& Pourshahian, 2012) have intended to identify the relationship between vocabulary learning strategy use and vocabulary size. All the recent studies mentioned above found that vocabulary learning strategies contributed to the overall vocabulary learning of the learners.

A number of studies, such as Şener_(2009) and Alemdari (2010), have examined the relationship between the use of vocabulary learning strategies and vocabulary size in the Turkish context. Firstly, in Şener (2009), it was revealed that Turkish students used many different strategies but they did not use mnemonic devices and semantic mapping and social strategies. It was also observed that students using vocabulary learning strategies more frequently did better in the Vocabulary Levels Test (VLT). Having a similar research design, Alemdari (2010) has concluded that students mostly preferred to use cognitive, determination and social strategies and found a relationship between successful vocabulary learning and use of cognitive and social strategies which were the categories favored most frequently by the successful learners in that population.

Recognizing the importance of strategy use in vocabulary learning, a number of researchers also focused on vocabulary learning strategy training. Alptekin (2007), in his study on foreign language learning strategy choice, investigated whether there were differences in language learning strategy preferences in tutored and in non-tutored conditions. The study of Aktekin and Güven (2007) on raising learners' and teachers' awareness on vocabulary learning strategy revealed that giving vocabulary learning strategy instruction to the study group had significant positive effect 
on the vocabulary learning of students. Atay \& Ozbulgan (2007) in their study on memory strategy instruction, contextual learning and ESP vocabulary recall, claimed that "the instruction seemed to help them to self-diagnose their learning difficulties, experiment with both familiar and unfamiliar strategies, and self-evaluate their performance" (p.47). Further, Kök and Canbay (2011) attempted to determine the effects of strategy training on vocabulary learning and use of vocabulary consolidation strategies in which a statistically significant difference between the experimental and control groups in favor of the experimental group at the vocabulary levels $1000 \mathrm{~B}$ and 2000 was found; however, there was no statistically significant difference between the groups at vocabulary level 1000A.

Heretofore, various studies have concentrated on identifying the strategies employed by EFL learners with reference to the variables such as age, gender, year of study, proficiency level and vocabulary size. In the current study, the issue of vocabulary learning and strategy use is investigated more elaborately using an additional data-gathering tool to get into the learners' vocabulary learning strategy use unlike most of the studies in the literature purely basing their findings on a questionnaire. Furthermore, this research demonstrates the presumable relationship between vocabulary learning and strategy use by measuring the vocabulary size of learners. Thus, the current study aims to investigate pre-service English teachers vocabulary learning strategy use and to determine whether it has an effect on their vocabulary size. A cross-sectional research design incorporating both quantitative and qualitative data gathering tools have been employed in the study guided by two research questions: (1) What are the least and most frequently used vocabulary learning strategies by pre-service English teachers? (2) Is there a relationship between pre-service English teachers' vocabulary size and vocabulary learning strategy use?

\section{METHOD}

To conduct an in-depth investigation, a cross-sectional research design was used in the study. Participants were 80 English Language Teaching (ELT) majors from 1st to 4th year at the Education Faculty of Anadolu University. Their experience as EFL learners ranged from nearly 10 to 14 years and their proficiency level was assumed to be advanced. In the study, each participant completed three instruments to be described below. As for the context of the study, the ELT program is consisted of four years and a prep year at the beginning of the program which can be exempted by passing a placement test. While the first year courses heavily focus on language skills, the rest of the program is mainly concerned with language teaching pedagogy and methodology. The program does not include a course focusing on vocabulary learning strategies, however, reading strategies are studied in the critical reading course.

Three different instruments were used in the study to investigate the relationship between pre-service English teachers' vocabulary size and vocabulary learning strategy use. Each was administered in a class hour in one-week interval. All the three instruments were in the target language, i.e. English. To measure the participants' vocabulary size, Vocabulary Levels Test (VLT) (Schmitt et al, 2001) was used in the study. The test is consisted of five sections consisted of four frequency bands, 2.000, 3.000, 5.000 and 10.000 word levels, and academic vocabulary that is not frequency-based. Each section includes ten clusters in which the participants are provided six target words and three meanings and they are asked to choose right target words to go with each meaning. Having thirty in each section, the test has one hundred fifty correct answers. Each correct answer is given one point. In the data analysis, the participants' overall scores are used. Rather than measuring a person's overall vocabulary knowledge, the test provides an estimate of vocabulary size at each of the frequency bands and an estimate of the size of academic vocabulary (Schmitt et al, 2001). The reason for preferring this test among alternative vocabulary size tests is the coverage of this test as involving all four word frequency levels as well as academic vocabulary.

As for examining the participants' vocabulary learning strategy use, based on Schmitt's taxonomy of vocabulary learning strategies (Schmitt, 1997), a 58-item Vocabulary Learning Strategy Questionnaire (VLSQ) was employed. It was administered one week later than the VLT since the VLT took half an hour for the participants to complete and it was not possible to administer the questionnaire just after the VLT because of the limited time. Schmitt's (1997) taxonomy was preferred in the study because it is a comprehensive taxonomy as well as it is the most widely used one in the literature on vocabulary learning strategies. However, some of the strategies in the taxonomy were adapted in terms of their wordings to make it more comprehensible for the target context. For example, the strategy "interacting with native speakers" was supplied with another expression in brackets "chatting online, face to face conversation etc.". The justification for this adaptation was that since the context was an EFL environment, the participants were less likely to interact with native speakers in person but on an online platform. Another adaptation was done for the strategy "asking the teacher for L1 translation" which was adapted as "asking someone (teacher, friend etc.) for L1 translation". The reason for this was that the participants were EFL teacher candidates and accepted as both proficient and autonomous learners which make it less likely for them to ask the teacher for L1 translation of a specific word. A few similar changes were also done in the questionnaire. Lastly, the Cronbach Alpha internal reliability coefficient of the questionnaire was calculated as .914 , which can be accepted as highly reliable. The questionnaire is consisted of five strategy categories based on Schmitt's (1997) taxonomy as described above. The first nine questions were related to determination strategies, the following eight questions to social strategies, the next twenty-seven questions to memory strategies, nine questions to cognitive strategies, and the last five questions were addressed to metacognitive strategies.

Besides the VLSQ, a Vocabulary Learning Strategy Survey (VLSS) (Appendix I) containing five situations that are likely to be encountered in real life was developed by the researchers both to support the data gathered through the 
VLSQ and to identify whether there would be some strategies employed by the participants which were not involved in the VLSQ. Being developed based on expert opinions, situations were designed considering different contexts that the participants may encounter such as reading something at home, listening to a lecture at school, watching TV, or interacting in a conversation, which can bring out unknown vocabulary. However, one of the situations had a general sense, asking participants whether they had a sufficient vocabulary and what they did to expand it, aiming to reveal any strategies used by the participants which were more systematic and used in long term. The participants were asked what they would do in the given situations to find out the meaning of the new word, and then to learn it. The reason for this two-fold question is that the taxonomy used in VLSQ contained strategies in two groups in general, i.e. strategies for discovering meaning and strategies for strengthening or reinforcing. The VLSS was administered one week later than the VLSQ. It was thought that the items in the VLSQ could affect the participants' responses and since the aim was to gather data on their own accounts of strategy use, a one-week interval would be more suitable rather than administering them one after another.

After the data were gathered, the analysis procedure was two-fold. Firstly, through descriptive statistics, most and least frequently used strategies in the VLSQ were identified and the participants' level of strategy use was determined, that is low (1.00-2.40), moderate (2.50-3.40) and high (3.50-5.00) based on Schmitt (1997) and Oxford (1990, 2001). Then, a repeated measures ANOVA was conducted to see whether there was a significant difference among the categories of strategies employed by the participants, which was followed by the participants' own accounts of strategy use gathered through the VLSS. Secondly, a hierarchical multiple regression test was conducted to identify whether the participants' scores in the VLT were affected by their reported strategy use in the VLSQ.

\section{RESULTS}

The most frequently used ten strategies in the VLSQ are identified using descriptive statistics and presented in Table 1. As seen on the Table 1, the most frequently used strategy is 'guessing from textual context' $(X=4.10, S D=0.794)$, which is followed by 'imaging word form' $(\mathrm{X}=3.93, \mathrm{SD}=1.003)$, 'connecting word to a personal experience' ( $\mathrm{X}=3.91$, $\mathrm{SD}=0.969)$, and 'analyzing any available pictures or gestures' $(\mathrm{X}=3.88, \mathrm{SD}=0.877)$. Thus, the importance of contextual clues is realized by the participants to a large extent.

TABLE 1.

VOCABULARY LEARNING STRATEGIES MOST FREQUENTLY EMPLOYED BY PRE-SERVICE ENGLISH TEACHERS IN VLSQ

\begin{tabular}{lll}
\hline & $\mathrm{X}$ & $\mathrm{SD}$ \\
\hline Guess from textual context & 4.10 & 0.794 \\
Image word form & 3.93 & 1.003 \\
Connect word to a personal experience & 3.91 & 0.969 \\
Analyze any available pictures or gestures & 3.88 & 0.877 \\
Say new word aloud when studying & 3.87 & 0.946 \\
Verbal repetition & 3.86 & 1.076 \\
Image word's meaning & 3.84 & 1.037 \\
Use English-language media (songs, movies, newscasts, etc) & 3.78 & 1.136 \\
Analyze part of speech & 3.77 & 0.993 \\
Take notes in class & 3.67 & 1.106 \\
\hline
\end{tabular}

On the other hand, as presented in Table 2, the least frequently used vocabulary learning strategy is 'asking someone to check flashcards or word lists for accuracy' $(\mathrm{X}=2.24, \mathrm{SD}=1.1)$, which is followed by 'flashcards' ( $\mathrm{X}=2.33$, $\mathrm{SD}=1.003)$, and 'listening to tape/CD etc. of word lists $(\mathrm{X}=2.36, \mathrm{SD}=1.003)$. These results show that the participants are quite autonomous in learning vocabulary and their use of word lists or flashcards less frequently can be explained by their proficiency level, which is also supported by their frequent use of contextual clues.

TABLE 2.

\begin{tabular}{|c|c|c|}
\hline & $\mathrm{X}$ & SD \\
\hline Ask someone to check flashcards or word lists for accuracy & 2.24 & 1.1 \\
\hline Flashcards & 2.33 & 1.003 \\
\hline Listen to tape/CD etc. of word lists & 2.36 & 1.105 \\
\hline Flashcards to study word meaning & 2.45 & 1.231 \\
\hline Underline initial letter of the word & 2.48 & 1.331 \\
\hline Put English labels on physical objects & 2.55 & 1.124 \\
\hline Word lists & 2.56 & 1.077 \\
\hline Interact with native speakers (chatting online, face to face conversation etc.) & 2.65 & 1.092 \\
\hline Group words together spatially on a page & 2.67 & 1.095 \\
\hline Use Keyword Method & 2.71 & 1.434 \\
\hline
\end{tabular}

As for the categories of strategies in the taxonomy of vocabulary learning strategies, the results are presented in Table 3. The participants most frequently employed determination strategies $(\mathrm{X}=3.353, \mathrm{SD}=0.4875)$. It is followed by memory $(X=3.241, S D=0.5212)$ and metacognitive strategies $(X=3.18, S D=0.5751)$. On the other hand, the least 
frequently employed strategies were cognitive $(X=3.016, S D=0.7509)$ and social strategies $(X=2.858, S D=0.635)$. So, the results demonstrated a moderate level of strategy use among participants.

TABLE 3.

THE MOST AND THE LEAST USED CATEGORIES OF STRATEGIES

\begin{tabular}{llll}
\hline & X & SD & Level \\
\hline Determination Strategies & 3.3533 & 0.48753 & Moderate \\
Memory Strategies & 3.2414 & 0.52124 & Moderate \\
Metacognitive Strategies & 3.18 & 0.57509 & Moderate \\
Cognitive Strategies & 3.0158 & 0.75087 & Moderate \\
Social Strategies & 2.8576 & 0.63495 & Moderate \\
Overall & 3.1658 & 0.43776 & Moderate \\
\hline
\end{tabular}

A repeated measures ANOVA was conducted to identify whether there was a significant difference among the strategy categories. The result of Mauchly's test of sphericity was found to be significant (Muchly's W(9)=.715, $p$ $<.01$ ), which means that sphericity assumption of ANOVA was not met in this analysis. Therefore, GreenhouseGeisser values are reported. The results of the repeated measures ANOVA revealed a significant difference among the strategy categories used by the participants, $F(3.488)=13.537, p<.001$. So, a paired samples t-test was conducted as a follow-up to identify which strategy categories significantly differed from others. The results showed that there was a statistically significant difference between determination strategies and all the other strategy categories: social strategies $(t(79)=6.178, p<.001)$, memory strategies $(t(79)=2.000, p<.05)$, cognitive strategies $(t(79)=4.079, p<.001)$, metacognitive strategies $(t(79)=2.506, p<.05)$. Moreover, there was also a statistically significant difference between social and memory strategies $(t(79)=-5.307, p<.001)$, social and metacognitive strategies $(t(79)=-3.636, p<.001)$, cognitive and metacognitive strategies $(t(79)=-2.217, p<.05)$, and lastly memory and cognitive strategies $(t(79)=3.158$, $p<.05)$. However, there was a non-significant difference between social and cognitive strategies $(t(79)=-1.912$, $p>.05)$, and memory and metacognitive strategies $(t(79)=.924, p>.05)$. The analysis revealed that besides being the most frequently used category, the use of determination strategies were also found to be statistically significant compared to all the other four categories in the taxonomy.

As described above, another data gathering tool, the VLSS, was used to both support the data collected through the VLSQ and to reveal any different strategies. After the content analysis process during which the main themes in the participants' responses were identified in negotiation of the two researchers, the frequency and percentages of these themes, or in other words, the participants' own accounts of strategy use were presented in Table 4.

TABLE 4.

FREQUENCY AND PERCENTAGES OF THE MAIN THEMES FROM THE VLSS

\begin{tabular}{|c|c|c|c|}
\hline & Frequency & Percentage & $\begin{array}{l}\text { Cumulative } \\
\text { Percentage }\end{array}$ \\
\hline Guessing from context & 99 & 21.47 & 21.47 \\
\hline Dictionary use & 91 & 19.73 & 41.20 \\
\hline Ask someone for meaning & 72 & 15.61 & 56.81 \\
\hline Online dictionary/web search & 54 & 11.71 & 68.52 \\
\hline Taking notes & 35 & 7.59 & 76.11 \\
\hline Using the word in a sentence/different sentences & 26 & 5.63 & 81.74 \\
\hline Reading books/novels/newspaper & 20 & 4.33 & 86.07 \\
\hline Repetition & 18 & 3.90 & 89.97 \\
\hline Skipping & 14 & 3.03 & 93.00 \\
\hline Watching TV series/movies & 13 & 2.82 & 95.82 \\
\hline Listening to English songs & 8 & 1.73 & 97.55 \\
\hline Interacting with friends in English (native/non-native speaker) & 3 & 0.65 & 98.20 \\
\hline Phone Dictionary & 2 & 0.43 & 98.63 \\
\hline Vocabulary notebook & 2 & 0.43 & 99.06 \\
\hline Analyzing root/affix/suffix of the word & 2 & 0.43 & 99.49 \\
\hline Sticking cards on the wall & 1 & 0.21 & 99.70 \\
\hline Make up a story & 1 & 0.21 & 100 \\
\hline Total & 461 & 100 & \\
\hline
\end{tabular}

As seen in Table 4, the most frequent theme or strategy in the participants responses was 'guessing from context', also supporting the VLSQ in which it was the most frequent one, as well. Furthermore, the second most frequent strategy was dictionary use and some participants specifically addressed to online tools to look up words which was the forth frequent strategy. But this was not the case in the VLSQ in which 'dictionary use' was reported to be used at a moderate level. 'Repetition' and 'English language media' which refers to watching movies, listening to songs, was also found in both data sources along with 'taking notes' and 'ask someone for meaning'. Despite of being very frequent, 'dictionary use' was not the first strategy that the participants preferred to employ. As seen in the quotations of two participants below, they mostly use dictionary only if they don't guess the new word from context or contextual clues such as gesture or mimics.

"I try to understand the meaning from context. If I can't understand, I check meaning from dictionary." (P1).

"If I can't find it from the context, I jot it down first, then check its meaning from the dictionary. (P2). 
As a frequently mentioned strategy, 'using the word in a sentence/different sentences' was not involved in the VLSQ. But obviously, it is, or believed to be, an effective way to learn a word.

"I try to guess the meaning first. Then I look it up in dictionary. And then, I use it in sentences." (P3).

There were also some individual strategies mentioned by only one or a few participants. Two of which are "making up a story' and 'sticking cards on the wall':

"I use the word in my own sentences, or if it is possible, I try to make up a story related to the word." (P4).

"I look up the word from the dictionary and write it down on a post-it, and stick it on my wall." (P5).

Most of the participants thought that they had had a larger vocabulary size before they started at the department. However, the results of the VLT do_not support this since the vocabulary size showed a developmental pattern among the year of study at the department. Furthermore, one of the participants stated that the VLT made her think that she didn't have a sufficient vocabulary size:

"Before the vocabulary test I took two weeks ago, I thought my vocabulary knowledge was sufficient. However, I noticed that it is not enough. Therefore, I've started to study a set of words I come across. ” (P6).

The results of the participants' performance in the VLT can be found in Table 5. Their overall mean score was 112.08, the maximum score of the test being 150. Figure 2 shows which sections of the VLT contributed to the participants' overall mean score, revealing their general performance in terms of vocabulary size.

TABLE 5 .

DESCRIPTIVE STATISTICS OF THE VLT IN TERMS OF OVERALL AND FREQUENCY WORD LEVELS

\begin{tabular}{llllll}
\hline & $\mathrm{N}$ & Min. & Max. & X & SD \\
\hline 2.000 level & 80 & 21 & 30 & 27.66 & 2.134 \\
3.000 level & 80 & 16 & 30 & 24.61 & 3.267 \\
Academic Vocabulary & 80 & 15 & 30 & 25.65 & 3.284 \\
5.000 level & 80 & 3 & 28 & 19.25 & 5.269 \\
10.000 level & 80 & 0 & 18 & 5.08 & 4.015 \\
Overall Size & 80 & 73 & 132 & 102.07 & 14.122 \\
\hline
\end{tabular}

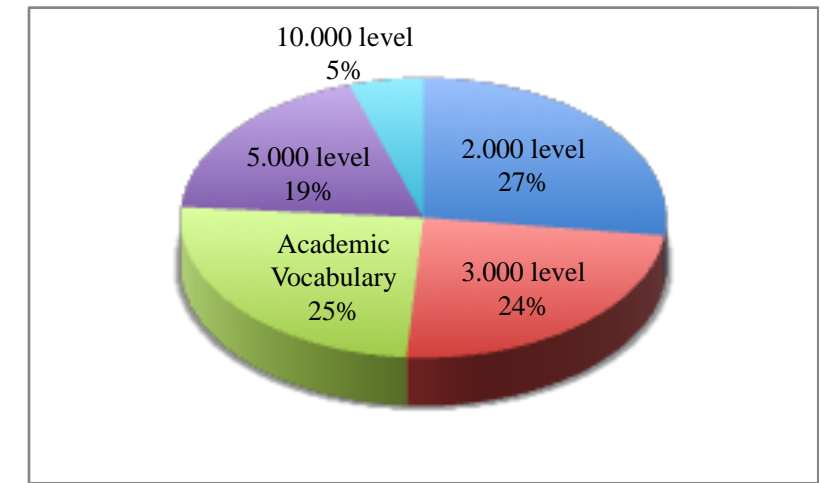

Figure 2. The distribution of the scores from each frequency band in the VLT

To identify whether a relationship exists between the participants' vocabulary size and vocabulary learning strategy use, a hierarchical multiple regression test was conducted. The dependent variable of the test was the participants' scores from the VLT and the dependent variables were the mean values of the strategy categories in the VLSQ. The results are presented in Table 6.

TABLE 6.

HiERARCHICAL MULTIPLE REgRESSION ANALYSIS (DEPENDENT VARIABLE: SCORES FROM THE VLT)

\begin{tabular}{|c|c|c|c|c|c|c|c|}
\hline Model & $\mathrm{R}$ & R Square & $\begin{array}{l}\text { Adjusted R } \\
\text { Square }\end{array}$ & $\begin{array}{l}\text { Standard } \\
\text { Error }\end{array}$ & F Model & $\begin{array}{l}\text { R Square } \\
\text { Change }\end{array}$ & F Change \\
\hline 1. Determination & .091 & .008 & -.004 & 14.15 & .652 & .008 & .652 \\
\hline 2. Social & .271 & .073 & .049 & 13.77 & 3.048 & .065 & $5.407^{*}$ \\
\hline 3. Memory & .271 & .074 & .037 & 13.86 & 2.015 & .000 & .027 \\
\hline 4. Cognitive & .356 & .127 & .08 & 13.54 & $2.721^{*}$ & .053 & $4.556^{*}$ \\
\hline 5. Metacognitive & .422 & .178 & .123 & 13.23 & $3.212^{*}$ & .052 & $4.647^{*}$ \\
\hline
\end{tabular}

The results revealed that vocabulary learning strategy use significantly explained $17.8 \%$ of the variation in vocabulary size. Controlling for all the other strategies, determination strategies did not explain any of the variation in vocabulary size although it was the most frequently used category of strategies. However, in spite of being the least frequently used category of strategies, social strategies were responsible for $6.5 \%$ of the variation in vocabulary size, which was statistically significant. Above and beyond other strategies, memory strategies did not explain any of the variation in vocabulary size. Yet, the unique contribution of cognitive strategies to vocabulary size was 5.3\%, and for metacognitive strategies, it is $5.2 \%$, which are again statistically significant. To sum up, controlling for memory and 
determination strategies having the least effect on the dependent variable, social, cognitive and metacognitive strategies explained $17 \%$ of the variation in vocabulary size.

\section{DISCUSSION}

As for the research question one focusing on what the least and most frequently used vocabulary learning strategies by Turkish EFL learners are, it was found that the participants reported 'guessing from textual context' as the most frequently used, which was also supported with the results of the Vocabulary Learning Strategy Survey (VLSS) and 'asking someone to check flashcards or word lists for accuracy' as the least frequently used strategy. If the major and proficiency levels of the participants are taken into consideration, it is self-evident that contextual clues have priority over accuracy and explicit learning for Turkish EFL teacher candidates. As for the categories in the taxonomy, the vocabulary learning strategies in all five categories are at a moderate level and the most frequently used one is determination strategies.

Although they mostly supported each other, the results of VLSS and the VLSQ in the present research have differed in some aspects. Unlike the VLSQ, in the VLSS, the second most frequently used strategy was dictionary use, which was also found in Hulstijin's (1993) study that good learners are more likely to consults dictionary to confirm their guesses about the meaning of words. Some participants specifically indicated that they use online tools to look up words as the forth-frequent strategy in VLSS. However, these results do not overlap with Schmitt's (1997) results as he had claimed that guessing often used without consulting a dictionary; yet the results of present study demonstrated that there is not a considerable difference between dictionary use and contextual guessing, because both strategies were used more often by students, which was found same in the study of Alamdari (2010), as well.

The most frequently used strategies by all subjects belonged to determination strategies that was statistically significant compared to all the other four categories in the taxonomy, while the social strategies were the least used ones by all subjects, which was consistent with the results of some previous studies (Hamzah et al , 2009; Şener, 2009; Komol \& Sripetpunn, 2011). However, the findings of some researchers, such as Kafipour, et al. (2011) and Heidari, et al. (2012) , indicated that memory strategy was the most frequently used strategy and cognitive strategy was the least frequently used one for Iranian EFL learners. Based on these results, it can be concluded that in different contexts strategy preferences of the learners may change. While the high use of determination strategies demonstrate the tendency of the pre-service English teachers in this study to discover the meaning by guessing from their structural knowledge of the language, from an L1 cognate, from context etc., the high use of memory strategies of Iranian EFL learners show that they have preferred vocabulary learning strategies which were simple with less need for mental activities and processing.

To answer the research question two regarding the relationship between the participants' vocabulary size and vocabulary learning strategy use, a hierarchical multiple regression test was conducted. The results revealed that vocabulary learning strategy use significantly explain $17.8 \%$ of the variation in vocabulary size. Although determination strategies are the most frequently used category, controlling for all the other strategies, it does not explain any of the variation in vocabulary size. However, the least used social strategies are responsible for $6.5 \%$ of the variation in vocabulary size, which is statistically significant. According to McComish (1990), if the learners exchange their ideas such as discussing how they remember words, giving some example sentences containing target word and so on with each other, it can improve their lexical knowledge. So, the students may need a push from the teacher by arranging suitable group work activities to enhance these interactions and exchange of ideas in learning new vocabulary (Komol \& Sripetpunn, 2011).

\section{CONCLUSION}

The current study indicated that Turkish teacher candidates of EFL demonstrate a moderate level of strategy use. Most of them adequately operated the determination strategies, whereas somewhat adequately the social strategies. Besides being the most frequently used category, the use of determination strategies was also found to be statistically significant compared to all the other four categories in the taxonomy. Moreover, it was proved that additional tools, such as the VLSS in the present study, have a role to support the data collection positively and reveal different strategies since the most frequent theme in the participants responses for the VLSS was 'guessing from context', also supporting the VLSQ in which it was the most frequent, as well. Furthermore, while 'using the word in a sentence/different sentences' was a frequently mentioned strategy in the VLSS, it was not involved in the VLSQ.

As for the vocabulary size of the learners, in VLSS, most of the participants stated that they had had a larger vocabulary size before they started at the department, yet the results of the VLT does not support this, since the scores showed a developmental pattern among as the year of study at the department increase. As a result, it can be concluded that the academic study of learners in university has a consistent effect on the vocabulary size of them. With regard to the relationship between vocabulary strategy use and vocabulary size, controlling for memory and determination strategies having the least effect, social, cognitive and metacognitive strategies explain $17 \%$ of the variation in vocabulary size. It means that the learners may need to operate a variety of strategies rather than certain ones. In other words, the participants of the current study may need more training on vocabulary learning strategies to become more 
familiar with all types as Oxford (2001) regard a good learner as the one applying all strategies in his/her learning at a high level.

In conclusion, it is remarkably essential to explore the vocabulary learning strategies, vocabulary size of the learners, and the relationship between them. They may help students, teachers, and administrators to become aware of vocabulary learning strategy profiles, vocabulary knowledge, and competency in order to design and deliver vocabulary instruction and training accordingly (Kalajahi \& Pourshahian, 2012) since, as Nation (2001) notes, strategy training has been proved to be very useful in broadening students' strategic knowledge. Therefore, especially the teachers have a vital role while helping learners to become aware of their own styles, preferences and habits for practicing their effective strategies. As a teacher, we should be able to get the learners to practice good strategies, and make them take charge of their own learning.

\section{REFERENCES}

[1] Alamdari, Z., S. (2010). The relationship between vocabulary learning strategies employed by university level English language learners and their success. Unpublished master's dissertation. Hacettepe University, Ankara.

[2] Alderson, J.C. (2005). Diagnosing Foreign Language Proficiency. London: Continuum.

[3] Alptekin, C. (2007). Foreign language learning strategy choice: naturalistic versus instructed language acquisition. Journal of Theory and Practice in Education (1): 4-11.

[4] Aktekin, C \& Guven, S (2007). Raising learners' and teachers' awareness of vocabulary strategy learning. Procedia Social and Behavioral Sciences. 13, 72.

[5] Atay, D., \& Ozbulgan, C. (2007). Memory strategy instruction, contextual learning and ESP vocabulary recall. English for Specific Purposes, 26, 39-51.

[6] Fan, M.Y. (2003). Frequency of use, perceived usefulness, and actual usefulness of vocabulary learning strategies: A study of Hong Kong learners. The Modern Language Journal, 87 (2), 222-241.

[7] Gu, Y. \& Johnson, R. K (1996). Vocabulary learning strategies and language learning outcomes. Language Learning, 46 (4), 643-679.

[8] Hamzah, S. G.; Kafipour, R. \& Abdullah, S. K. (2009). Vocabulary learning strategies of Iranian undergraduate EFL students and its relation to their vocabulary size. European Journal of Social Sciences, 11(1). 39-50.

[9] Heidari, F.; Izadi, M. \& Ahmadian, M. (2012). The Relationship between Iranian EFL learners“ self-efficacy beliefs and use of vocabulary learning strategies. English Language Teaching, 5(2), 174-182.

[10] Hulstijn, J. H. (1993). When do the foreign language readers look up the meanings of unfamiliar words? The influence of task and learner variables. Modern Language Journal, (77), 139-147.

[11] Kafipour, R.; Yazdi, M.; Soori, A. \& Shokrpour, N. (2011). Vocabulary levels and vocabulary learning strategies of Iranian undergraduate students. Studies in Literature and Language, 3(3), 64-71.

[12] Lawson, M. J., \& Hogben, D. (1996). The vocabulary learning strategies of foreign-language students. Language Learning journal, 46, 101-135.

[13] Kalajahi, S. \& Pourshahian, B. (2012). Vocabulary learning strategies and vocabulary size of ELT students at EMU in Northern Cyprus. English Language Teaching, 5(4), 138-149.

[14] Komol, T. \& Sripetpun, W. (2011). Vocabulary learning strategies employed by undergraduate students and its relationship to their vocabulary knowledge. Proceedings of the 3rd International Conference on Humanities and Social Sciences, Prince of Songkla University.

[15] Kök, İ. \& Canbay, O. (2011). An experimental study on the vocabulary level and vocabulary consolidation strategies. Procedia Social and Behavioral Sciences, 15, 891-894.

[16] Laufer, B. (1992). How much lexis is necessary for reading comprehension? In P. J. L. Arnaud and H. Be' joint (Eds.), Vocabulary and applied linguistics (pp. 126-132). London: Macmillan.

[17] Laufer, B. and Goldstein, Z. (2004). Testing vocabulary knowledge: Size, strength, and computer adaptiveness. Language Learning 54, 3: 399-436.

[18] Lip, P. (2009). Investigating the Most Frequently Used and Most Useful Vocabulary Language Learning Strategies among Chinese EFL Postsecondary Students in Hong Kong. Electronic Journal of Foreign Language Teaching, 6(1), 77-87.

[19] McComish, J. (1990). The word spider: a technique for academic vocabulary learning in curriculum area. Guideline, 12, 26-36.

[20] Nation, I. (2001). Learning Vocabulary in Another Language. Cambridge: Cambridge University Press.

[21] Oxford, R. (1990). Language learning strategies: What every teacher should know. New York: Newbury House.

[22] Oxford, R. (2001). Language learning strategies. In R. Carter \& D. Nunan, The Cambridge Guide to Teaching English to Speakers of Other Languages. (pp. 166-171). Cambridge: Cambridge University Press.

[23] Rubin, J. (1987). Learner strategies: theoretical assumptions, research history and typology. In A. Wenden and J. Rubin (Eds.) Learner Strategies in Language Learning. New York: Prentice Hall.

[24] Schmitt, N. (1997). Vocabulary learning strategies. In N. Schmitt \& M. McCarthy (Eds.), Vocabulary: description, acquisition and pedagogy (pp.199-228). Cambridge: Cambridge University Press.

[25] Schmitt, N., Schmitt, D., \& Clapham, C. (2001). Developing and exploring the behavior of two new versions of the vocabulary levels test. Language Testing, 18, 55-88

[26] Schmitt, N. (2010): Researching vocabulary: A vocabulary research manual. Hampshire, England: Palgrave Macmillan.

[27] Şener, S. (2009). The Relationship between Vocabulary Learning Strategies and Vocabulary Size of Turkish EFL Students. Retrieved from http://yadem.comu.edu.tr/3rdELTKonf/spkr_sabriye_sener.htm on May 11th, 2012.

[28] Wilkins, D.A. (1972). Linguistics in Language Teaching. London \& NY: Longman. 
Seray Tanyer is a graduate research and teaching assistant at Anadolu University, Eskisehir, Turkey. She is currently working on her MA thesis in EFL writing. Her research interests mainly include teaching vocabulary and writing, classroom interaction, corpus linguistics and academic discourse.

Yusuf Ozturk is a graduate research and teaching assistant at Anadolu University, Eskisehir, Turkey. He is currently working on his MA thesis which focuses on recurrent multi-word expressions in academic texts. His research interests mainly include technology integration into teaching, vocabulary teaching, formulaic language, academic discourse and corpus linguistics. 